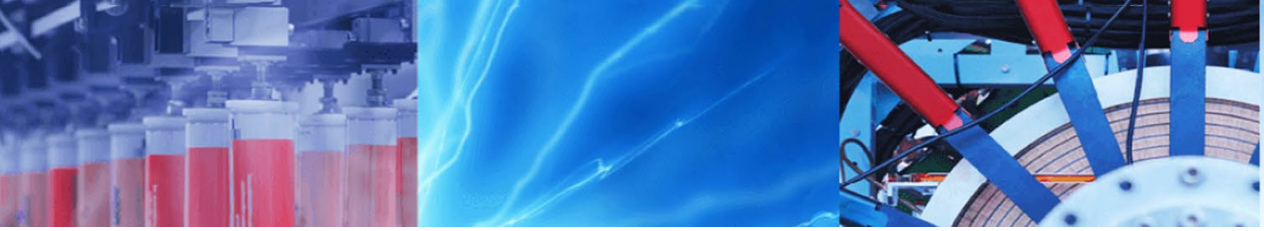

Research Article

\title{
Sedimentology, depositional environment and classification of Karkheh River's Delta, West of Khuzestan Plain (SW of Iran)
}

\author{
Ahmad Abyat $^{1}$ [D $\cdot$ Ali Azhdari $^{1} \cdot$ Amir Feghhi $^{2} \cdot$ Mohammd Judaki $^{3}$
}

Received: 26 July 2020 / Accepted: 21 December 2020 / Published online: 15 January 2021

(C) The Author(s) 2021 OPEN

\begin{abstract}
Karkheh river's Delta is located in the west of Khuzestan Plain and can be divided into two smaller deltas; northern delta named as Karkheh Delta (including Bostan, Sableh and Neisan Deltas) and southern delta named as Karkheh -e- Noor Delta. Based on Galloway7 classification, Karkheh Delta is river-dominated type (type 1). Considering activity, this delta is divided to two parts; an active part in north and an inactive part in south. Based on Orton and Reading 16 classification, Karkheh Delta is placed in fine-grained (muddy) delta category due to prevailing silt and clay. In terms of sediment transportation and deposition process, this delta is a constructive delta. To recognize changes of Karkheh Delta's area, Landsat images 5, 7 and 8 were studied and compared using 13 satellite images from 1973 to 2016 which shows an increase in the delta's area particularly in northern part. In order to study sedimentology of this delta, 25 samples were taken. Sediment sizing analysis results show that silt is the most abundant sediment on average in this delta whereas clay, sand and gravel are in next abundance. Due to Shepard 17 classification, in Karkheh delta, silty clay, clay silt, silt, sandy silt and clay-silt-sand were identified. Also, channel, flood plain, crevasse, levee and sabkha depositional environments could be recognized in this delta.
\end{abstract}

Keywords Delta $\cdot$ Karkheh $\cdot$ Khuzestan plain $\cdot$ Karkheh -e- nor $\cdot$ Depositional environment

\section{Introduction}

Khuzestan Plain is one of sub-areas of Zagros Basin located in southwest Iran. Top of this plain is covered by coarsegrained alluvial sediments in north and fine-grained in south. The Lower Khuzestan plain, forming the eastern extension of the Mesopotamian Plain, is bordered in the north and east by the foothills of the Zagros Mountains [10].

The known continental Quaternary depositional environments in Khuzestan Plain involve alluvial fans, fluvial, aeolian sands, deltas, sabkhas and lagoons [2]. Delta is one of transitional depositional environment which has a triangular shape such that its head towards the river and its base towards the sea, gulf, lagoon or lake.
The identified deltas in Khuzestan Plain are Karoon, Karkheh, Jarrahi and Zohreh Deltas [2, 3]. In this research, sedimentology, depositional environment and classification of Karkheh Delta in west of Khuzestan Plain were studied. Karkheh Delta is located in west of Khuzestan and between northern latitude of $31^{\circ} 25^{\prime} 30^{\prime \prime}-31^{\circ} 47^{\prime} 42^{\prime \prime}$ and eastern longitude of $47^{\circ} 49^{\prime} 30^{\prime \prime}-48^{\circ} 12^{\prime} 01^{\prime \prime}$. Head of this delta is in Susangerd city, ends to Hor Al-Azim marsh and geographically is limited between Susangerd, Bostan, Rofaieh and Howeyzeh. Since in this article, type determination of Karkheh Delta in conventional classification is an aim, it is necessary to say a summary about different types of deltas classification. So far deltas are classified in different ways. The most important classification was done by Galloway [7] in which deltas based on type of process

Ahmad Abyat, Ahmadabyat@gmail.com | 1 Geological Survey of Iran, Ahwaz, Iran. ${ }^{2}$ Department of Petroleum Engineering, Islamic Azad University, Omidieh brunch, Omidieh, Iran. ${ }^{3}$ Geological Survey of Iran, Tehran, Iran. 
are divided into three groups, river-dominated, wavedominated and tide-dominated. Based on the activity of the deltas are divided into two types: active and inactive deltas. Deltas can be also classified according to sediment transportation and deposition; constructive and deconstructive deltas. Orton and Reading [16] mentioned the role of sediments size on delta classification and based on this, four groups were made, fine-grained (muddy), fine sand, gravelly sand and gravel.

So far, several studies were done about deltas of earth, most 6important of which are Galloway [7], Wright [18], Orton and Reading [16], Coleman and Huh [16], Kuenzer et al. [13], Petropoulos et al. (2015) and Zheng et al. [19]. However, few studies about sedimentology, depositional environment and area changes of Karkheh Delta have been done. In terms of sedimentology and depositional environment, Abyat et al. [1] and then Abyat et al. [2, 3] did the first research on this delta. Moreover, Abyat et al. [2, 3] performed some research about depositional environments of Late Quaternary in Khuzestan Plain.

\section{Method of study}

This research is a part of the study done on the Quaternary depositional environment of Khuzestan Plain. In the beginning step, data like reports, articles, topographical and geological maps, aerial images etc. were gathered. Then, using satellite images, topographical and geological maps, Karkheh Delta and the near depositional environments were distinguished. In the next step, field sampling was planned. In this research, 25 samples were taken from Karkheh Delta (Fig. 1). In sampling stage, almost 2500 gr. of sediment were taken from the surface to depth of $30 \mathrm{~cm}$. About $250 \mathrm{gr}$. of each sample was sent to the lab for sediment sizing, for which wet shaker sieve and laser particle sizer devices were used. Since the most of samples were fine-grained, Shepard [17] method was applied for denomination. Shepard [17] classification excels Folk (1974) classification for fine-grained sediments. This classification uses SEDPLOT and GSSTAT softwares. At the end, the final map of Karkheh Delta and its neighboring environments was drawn using Google Earth and ArcGis 10.3.

In order to analyze changes in Karkheh Delta's area, satellite images came in use. Progression and regression of deltas can be studies via maps and aerial images in defined time intervals (Bird) [5]. Satellite Images Landsat 1-5MSS, Landsat 5 TM, Landsat 7 ETM and Landsat 8 (from 1973 to 2016) were used. Based date of images is June, since in this time there is no mendacious input (unexpected winter rain) and therefore real delta's area is seen. Specifications of the received images are shown in Table 1. ENVI 5.3 software was used to process the images. The band combinations used to separate aquatic area of Hor Al-Azim marh from the delta in this research are shown in Table 1. Finally, using ArcGIS 10.3 software, delta limits during different years was identified and its area was calculated.

\section{Discussion and results}

As mentioned before, Karkheh Delta is located between Dasht-e- Azadegan and Howeyzeh cities and begins as Karkheh river branches in Susangerd city. Like Jarrahi Delta, Karkheh Delta also enters into a marsh named as Hor Al-Azim or Hor Al-Howeyzeh. Catchment basin

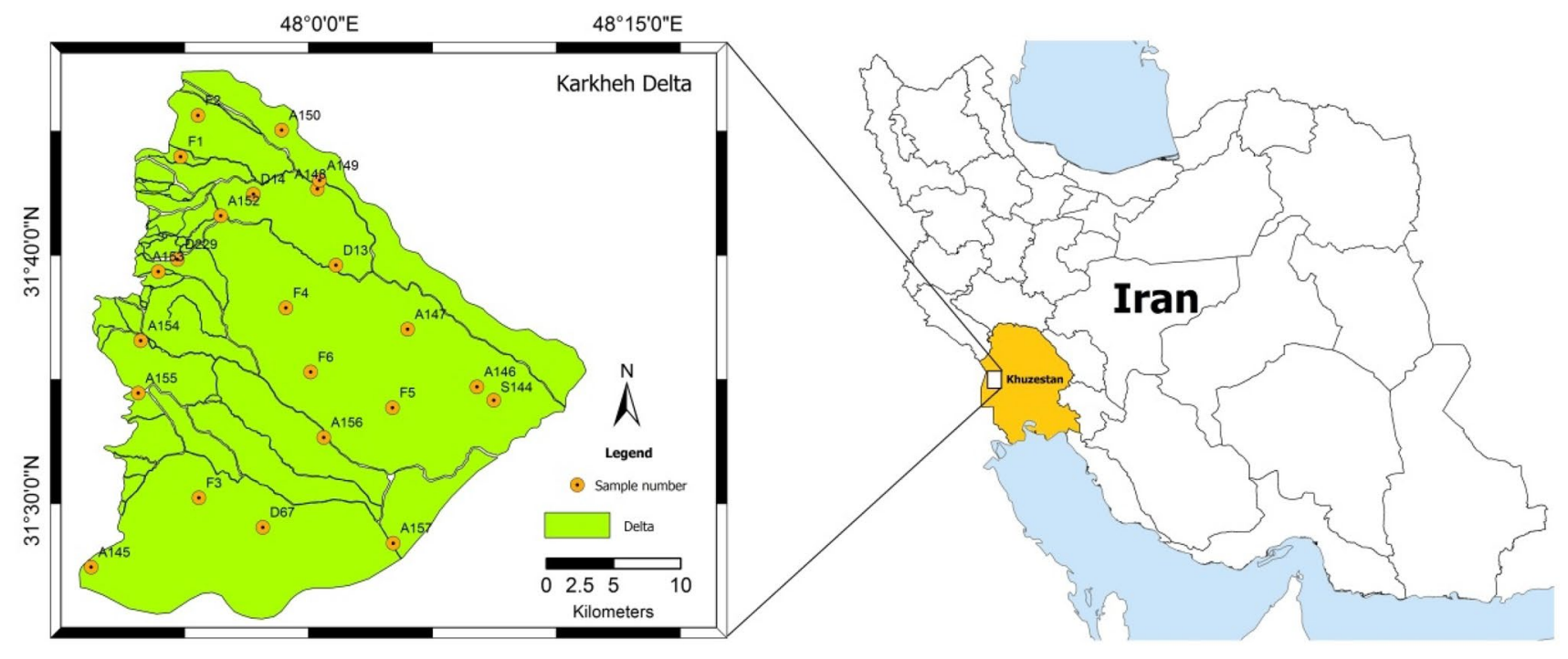

Fig. 1 Location of the study area and samples taken 
Table 1 Description of landsat data used in this study

\begin{tabular}{llll}
\hline Platform/Sensor & Source & Year & Path/Row \\
\hline L1-5/MSS & USGS & 1973 & $178 / 39$ \\
L5/TM & USGS & 1977 & $179 / 38$ \\
& USGS & 1985 & \\
& USGS & 1990 & \\
& USGS & 1993 & \\
& USGS & 1998 & \\
L7/ETM & USGS & 2000 & \\
& USGS & 2004 & $165 / 39$ \\
& USGS & 2007 & $166 / 38$ \\
& USGS & 2010 & \\
L8/OLI & USGS & 2012 & \\
\hline
\end{tabular}

of Karkheh river has an area of $51,643 \mathrm{~km}^{2}$. Average of Karkheh river flow rate in Hamidiyeh Station in recent 62 years is $134.2 \mathrm{~m}^{3} / \mathrm{s}$. Karkheh delta has a triangular shape and its base is almost smooth (Fig. 2). Height of this triangle is $37 \mathrm{~km}$, its base is $41 \mathrm{~km}$ and has an area of $879 \mathrm{~km}^{2}$. The full triangular shape of this delta shows that waves and tides lack any impact on its formation. This delta from northeast limits to Fars Group outcrop in Band-e-Karkheh anticline and its alluvial fans, from north to Om-Al-Debes sand dunes, from southeast to Karkheh flood plain, from south to Karoon west sabkha and from west to Hor Al-Azim marsh (Fig. 3).

Three main channel belts of the Karkheh were identified (labelled Kh1, Kh2 and Kh3) by Heyvaert et al. [10]. Abyat et al. [1] divided Karkheh river channel into three intervals which the third one (Hamidiyeh to Hor Al-Azim) is placed in Karkheh Delta. In this interval, Karkheh is a combination of straight and meandering shapes. From Hamidiyeh Dam towards Bostan, Karkheh Channel almost has a straight path after which the river continues in a slight meandering shape to Hor Al-Azim marsh. This section is highly branched and in fact is the Karkheh Delta. The main channel of Karkheh delta is Kh3b which forms northeast-southwest side of this delta, starts from Susangerd, continues to Bostan City and finally enters into the marsh. The other channels of this delta are Kh2b, $\mathrm{Kh} 2 \mathrm{c}, \mathrm{Kh} 2 \mathrm{~d}$ and Kh3c. unlike the Karoon Delta and like

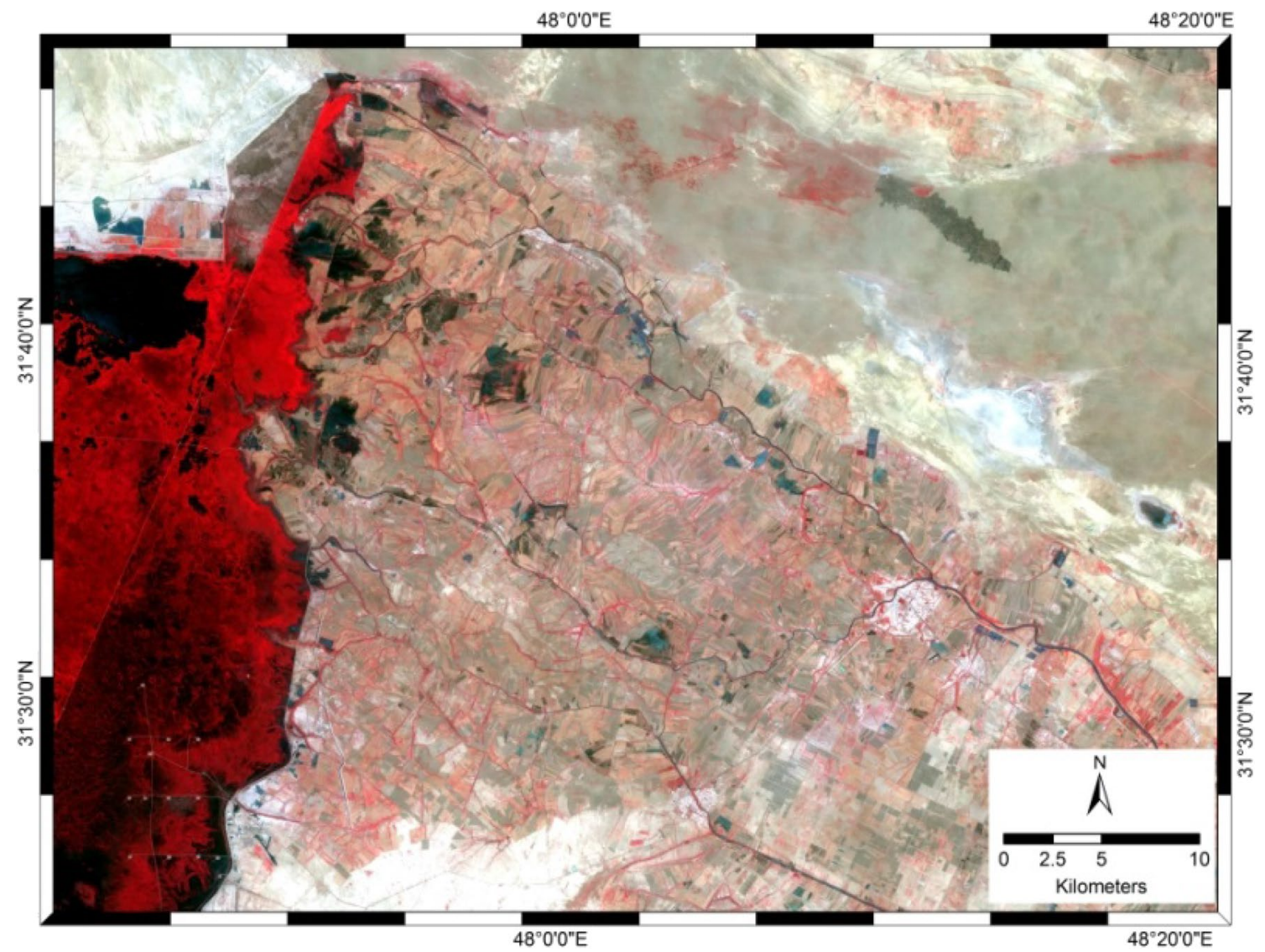

Fig. 2 The Landsat 8 satellite image of the Karkheh Delta and adjacent environments 


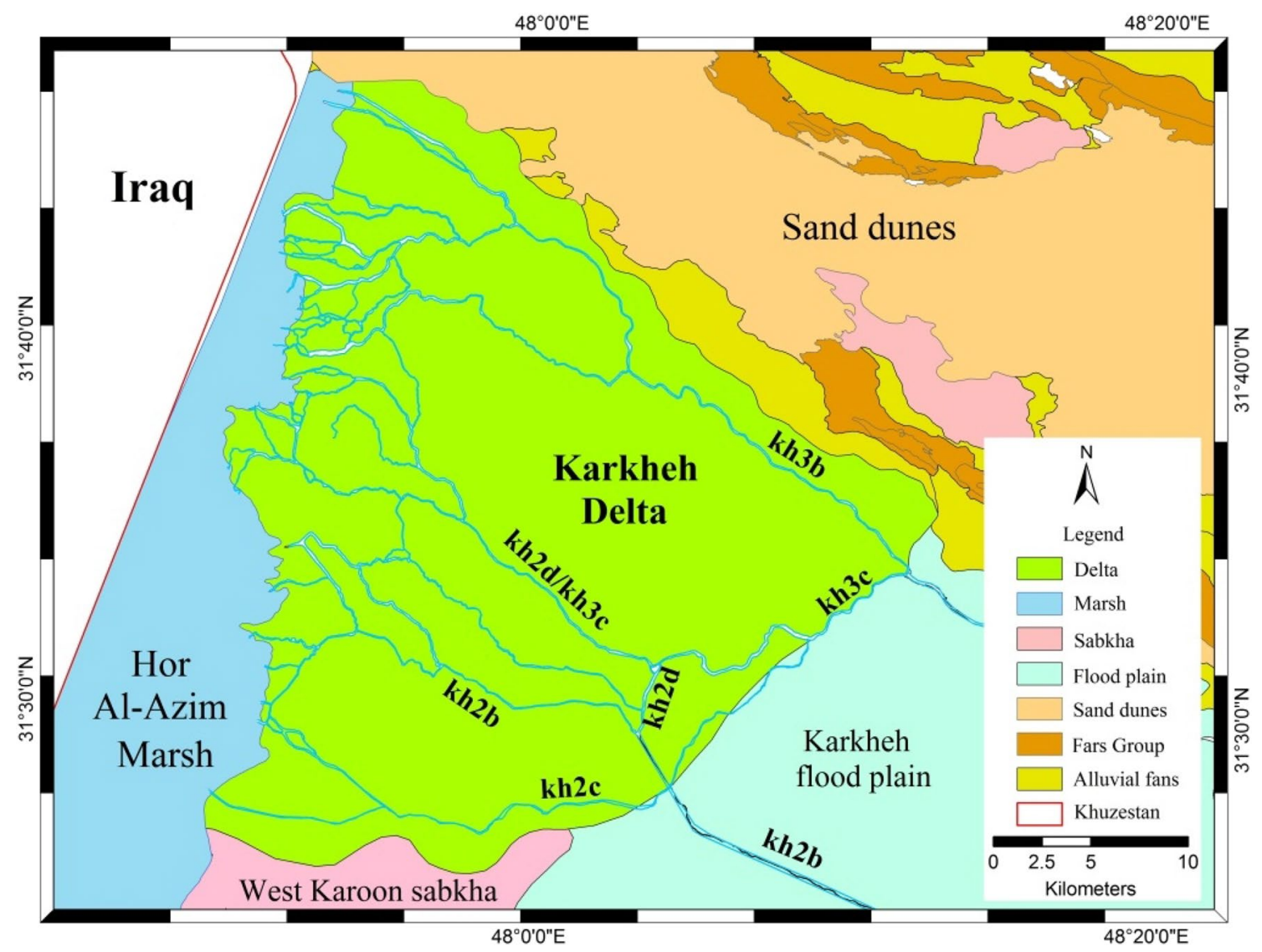

Fig. 3 Karkheh Delta and adjacent environments of this Delta

Jarrahi Delta, this delta is intensively branched (Abyat et al.) $[2,3]$ with many branches (Fig. 4).

In a large-scale view regarding the main existing channels, Karkheh Delta can be divided to two deltas; northern delta named as Karkheh Delta and southern delta named as Karkheh -e- Noor Delta. Northern Delta is more extensive and is located between Kh3b (Karkheh/Bostan) and Kh3c/Kh2d (Karkheh -e- Noor/Neisan) channels. Approximate length of $\mathrm{Kh} 3 \mathrm{~b}$ is $38 \mathrm{~km}$ (without calculating curve sections), for $\mathrm{Kh} 3 \mathrm{c}$ channel is $14 \mathrm{~km}$ and for $\mathrm{Kh} 3 \mathrm{c} / \mathrm{Kh} 2 \mathrm{~d}$ is about $25 \mathrm{~km}$ (length of this side is totally $39 \mathrm{~km}$ ). Base of delta from the tongue of two channels is $21 \mathrm{~km}$. Delta's total area is about $568 \mathrm{~km}^{2}$. This delta from north to south is divided into three smaller deltas named as Bostan, Sableh and Neisan. Bostan Delta has a main river called Bostan river and an area of almost $57 \mathrm{~km}$, Sableh Delta getting its name from Sableh river (from Sableh village; dependencies of Bostan city) has approximately an area of $45 \mathrm{~km}$ and Neisan Delta from the river with the same name (from Neisan city) has an area of $60 \mathrm{~km}$ (Fig. 5).

The second delta which is southern delta or Karkheh -e- Noor Delta is placed between Kh3c/Kh2d (Karkheh -e- Noor/Neisan) and Kh2c (Karkheh -e- Noor) channels and is smaller than the northern delta. The approximate length (without considering curve sections) of $\mathrm{Kh} 2 \mathrm{C}$ is $20 \mathrm{~km}$. The base of this delta from tongues of two channels is almost $20 \mathrm{~km}$ long and has an approximate area of $312 \mathrm{~km}^{2}$. This delta has less branches and flow rate decreases. Most of main branches of this delta is humanmade and are not natural.

\subsection{Karkheh delta's dip}

Karkheh Delta's dip is from east towards west. Actually, its head is in east and its base in west. The minimum altitude is $-8 \mathrm{~m}$ and the maximum one is $28 \mathrm{~m}$ sub-sea depth. Dip change is very gradual (Fig. 6). The relationship between sediment size and slope is non-linear with slope increasing more rapidly than grain size [11, 12]. As Hooke and Roher (1979) and Howard [12] mention, fine-grained deltas have a slight dip. Karkheh Delta is fine-grained and as expected it has a low dip of $0.1^{\circ}$ per $\mathrm{km}$. Amongst low-dip deltas, Mississippi delta in United States, Ganges-Brahmaputra in Bangladesh-India and Amazon in Brazil can be named. 


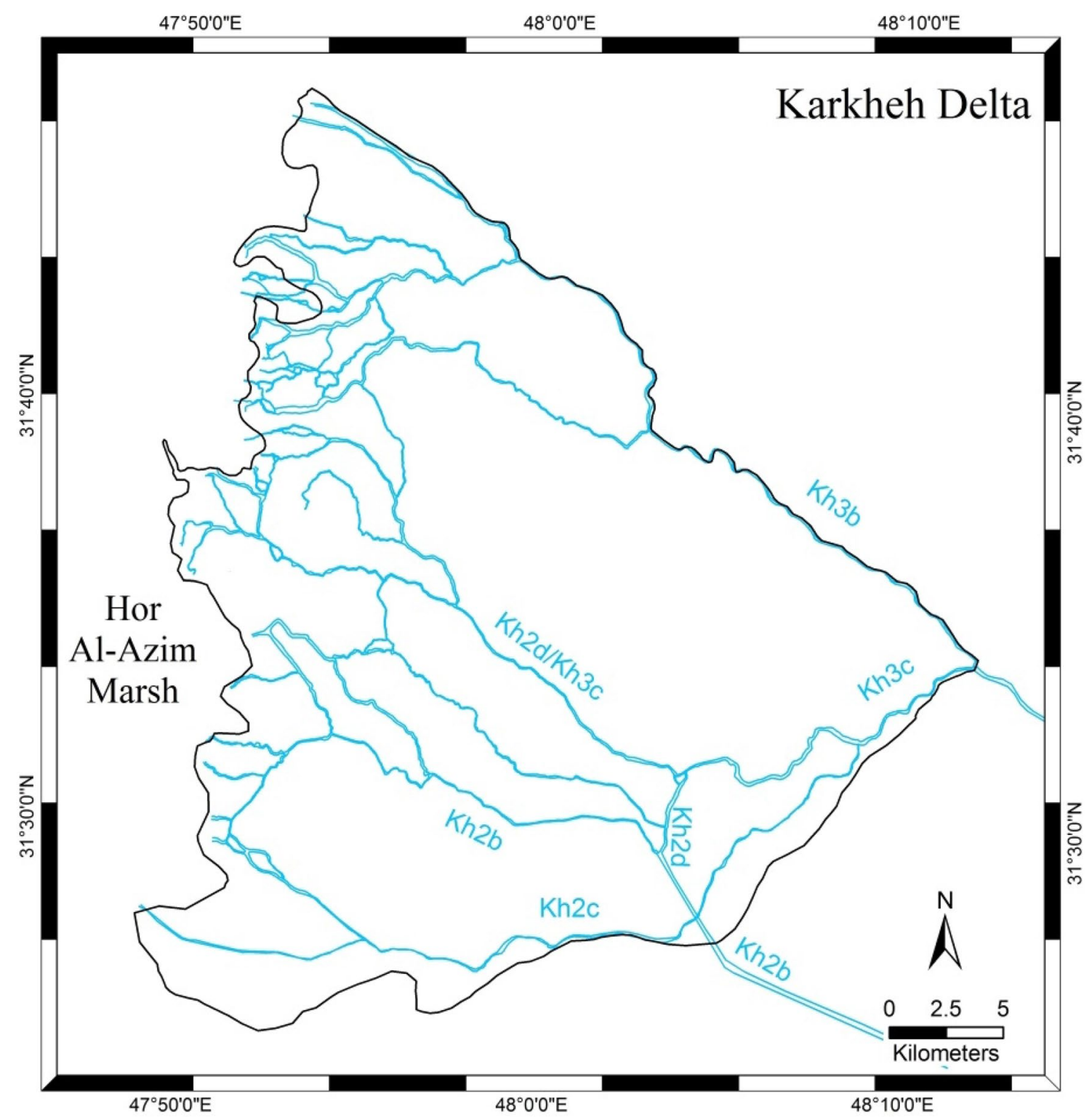

Fig. 4 Karkheh River and its branches in the Karkheh Delta

\subsection{Classification of Karkheh delta}

Being active or inactive, this delta can be divided into two parts; 1- Active delta: in which deposition takes place at the moment and is placed between Kh3b channel in north and Kh2c channel in south. As mentioned before, this delta can be split to northern and southern deltas which the northern one (between Kh3b and Kh3c/Kh2d) is more active than the southern one (between $\mathrm{Kh} 3 \mathrm{c} / \mathrm{Kh} 2 \mathrm{~d}$ and $\mathrm{Kh} 2 \mathrm{c}$ ). 2-Inactive delta which is placed between $\mathrm{Kh} 2 \mathrm{C}$ and Kh1 channels. In fact, Kh1 channel is the first channel of Karkheh river which became inactive by passing time. As it is shown this area has changed to sabkha named as west karoon sabkha (Fig. 4). Deviation of river path and being inactive delta has been reported for Huang He river in China, Rioni in Georgia, seyhan river in Turkey and Medjerda river in Tunesia.

Galloway [7] has introduced three main shapes of delta based on the domination of controls, tidal waves and their intermediate forms. In other words, three types of river-dominated delta, wave- dominated delta and tidal delta can be distinguished and investigated. According to this classification Karkheh Delta is of overdominated variety (Type-I) (Fig. 7). Absence of tidal waves at the mouth of delta, perceptible dominance of river current in generating delta, gentle slope of deltaic plain, fine-grained silt and, sporadically, clay sedimentary load, infrequent coarse sediments and being 
Fig. 5 The main Karkheh delta and its smaller deltas

Fig. 6. Map of the Karkheh Delta slope
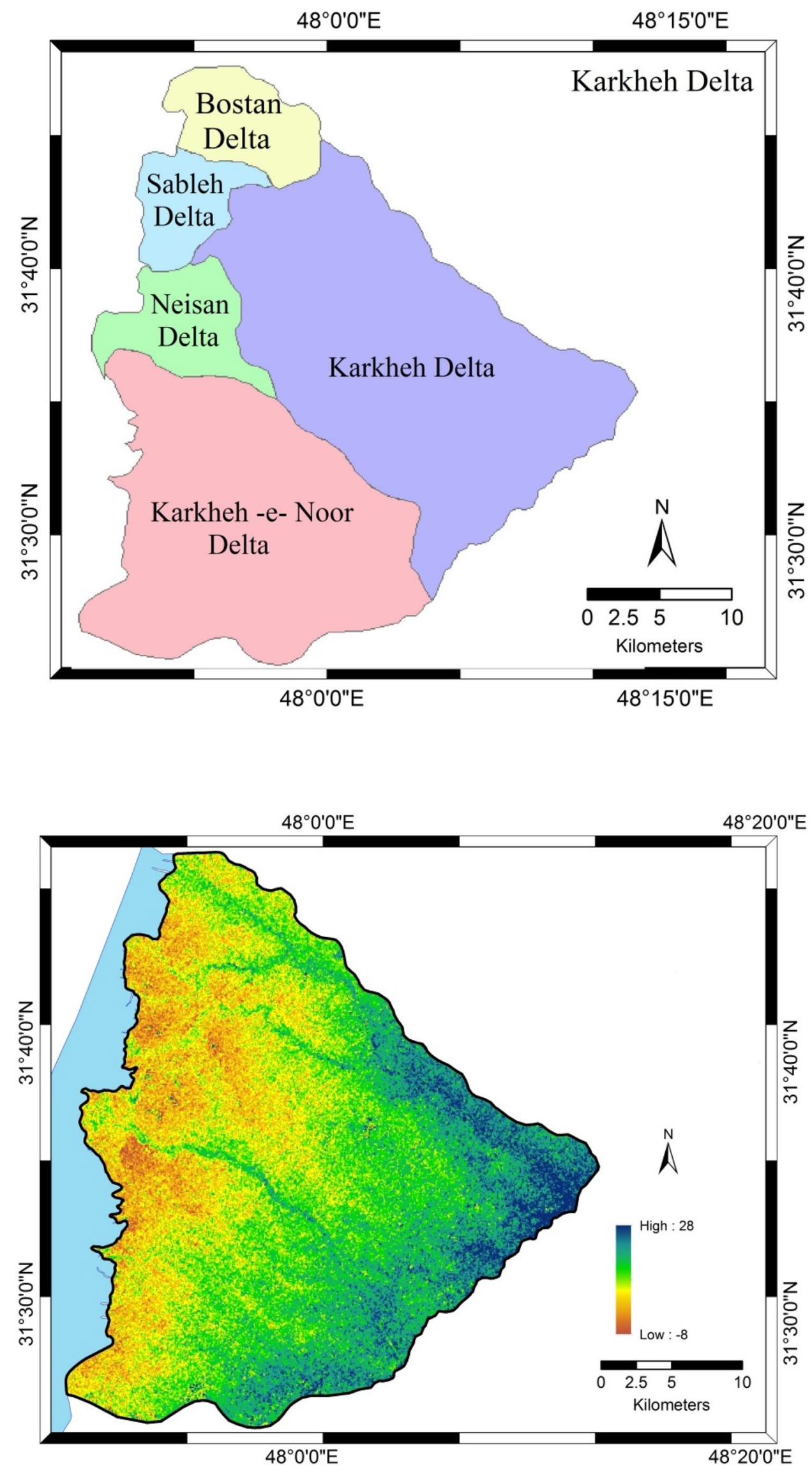


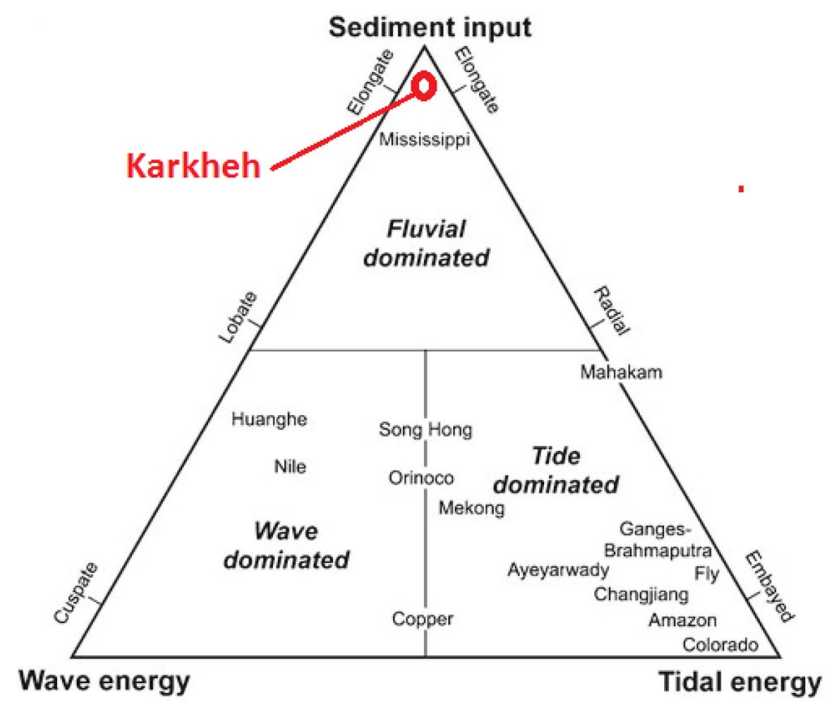

Fig. 7 Karkheh Delta position in Galloway (1975) classification (After Goodbred and Saito 2012)

land-locked all appertain to river- dominated characteristic of Karkheh Delta. In this delta, sediments orient parallel to slope of the depositional basin, which has been occasioned by the E-W trend/dip of the delta. Mississippi delta in United States, Danube in Romania, Po in Italy, MacKenzie in Canada, Aalta and Tunsberg dalbre in Norway and Huang $\mathrm{He}$ in China are the most important river-dominated deltas which except for Mississippi, in the other deltas tides and waves have little impact. Also, Jarrahi delta in Khuzestan is a river-dominated one [1, 3].

Considering Orton and Reading [16] classification which remarks role of sediments' size in classifying deltas, Karkheh delta is placed in fine-grained (muddy) deltas group due to domination of its silt and clay. Amongst river-dominated deltas, Mississippi, Po and Huang $\mathrm{He}$ are fine-grained type, Mackenzie is finesand and Aalta and Tunsberg dalbre are gravel type. Characteristics of Karkheh Delta are having big area of catchment basin, little unevenness, warm climate, small width to depth ratio of channels, low lateral migration and slight dip of delta plain. Such specifications are special for fine-grained deltas. In Khuzestan, Karoon and Jarrahi are fine-grained deltas [2].

In terms of transport and deposition process, Karkheh Delta belongs to constructive deltas. Comparing aerial images from 1973 to 2016, it is confirmed that this rive is constructive (Figs. 8, 9, 10, 11 and Table 2). Offloading a great mass of sediments in this short time interval resulted in increase of land area in this part.

\subsection{Changes in Karkheh delta's area by passing time}

In order to know changes in Karkheh Delta's area, Landsat 5, 7, 8 images were analyzed and compared using 13 satellite images from 1973 to 2016 . Being similar to Karoon and Jarrahi Deltas, an increase in area (particularly in the northern part of delta) can be observed in this delta (Figs. 8, 9 and 10). In the year 1973, the delta had an area of $783.3 \mathrm{~km}^{2}$, however in 2016 this value reached to 817 $\mathrm{km}^{2}$ (Fig. 11 and Table 2). This acknowledges that Karkheh Delta is constructive. Indeed, in some years, decrease in delta's area can be seen. For instance, from 1990 to 1998, decrease in area can be clearly observed. Karkheh Delta is constructive because of Karkheh river's sediments load and decrease in Hor Al-Azim Marsh's area.

As it is shown in figures, the northern part of Karkheh Delta had a huge progression, however we can see a smaller expansion in the southern part (Fig. 10). Heyvaert et al. [10] studies show that southern channels of Karkheh Delta are older comparing with the middle and northern channels. This shows higher activity of north of delta such that due to being older and also human activities, the southern channels are mostly inactive and therefore there does not exist much progression in this part. In this section of delta, there are fewer branches and their flow rate is also low. In contrary, towards north of delta, we can see more branches, higher flow rate and finally a higher progression in delta.

\subsection{Sedimentology of Karkheh delta}

In order to study sedimentology of this delta, 25 samples were taken (Fig. 1). Sediment sizing analysis results show that silt is the most abundant sediment in this delta on average $48.05 \%$. After silt, clay with $35.3 \%$, sand with $16.2 \%$ and gravel with $0.44 \%$ are in next abundance (Fig. 12 and Table 3). Gravel percentage in samples of Karkheh delta changes between 0.28 and $0.55 \%$, sand between 4.61 and $43.25 \%$, silt between 45.57 and $53.78 \%$ and clay between 10.9 and $48.7 \%$ (Table 3, 4) .

In Fig. 13, distribution of different sediments in Karkheh Delta is shown according to Shepard .[17] As mentioned before, Karkheh Delta has an east-west dip such that its head is in east and its base in west.

Percentage of gravel and its changes in this delta is negligible and its distribution map is irregular. The maximum value of gravel is seen in south of delta in vicinity of western Karoon sabkha and also in northeast of delta in vicinity of Fars Group alluvial fans (Band-e-Karkheh anticline). In northwest of delta, its value decreases such that it reaches to the minimum because of being in vicinity of mature sand dunes. 


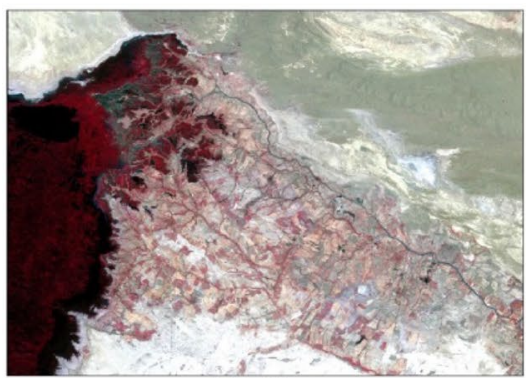

1973

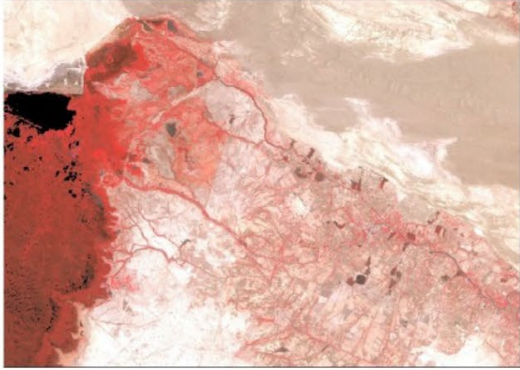

1990

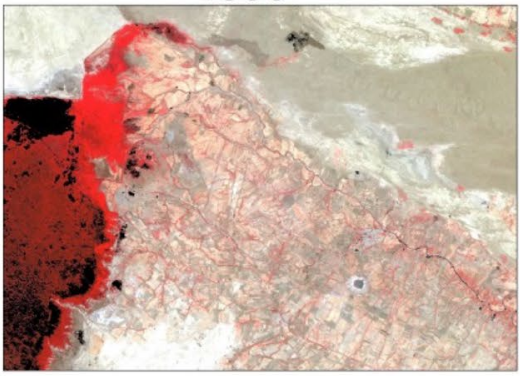

2000
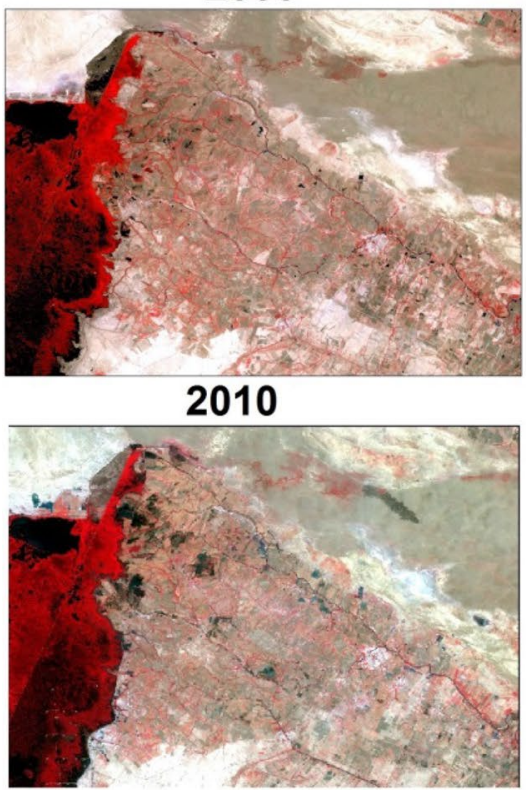

2016

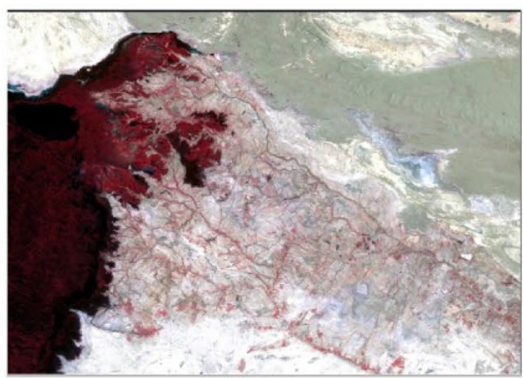

1977

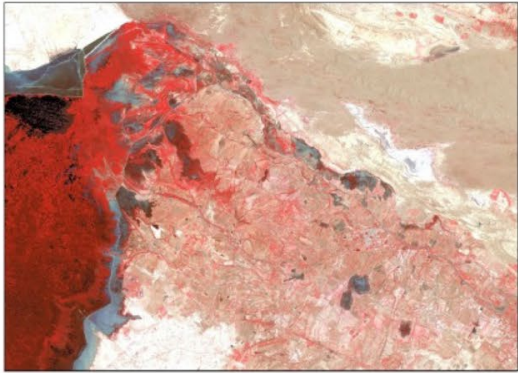

1993

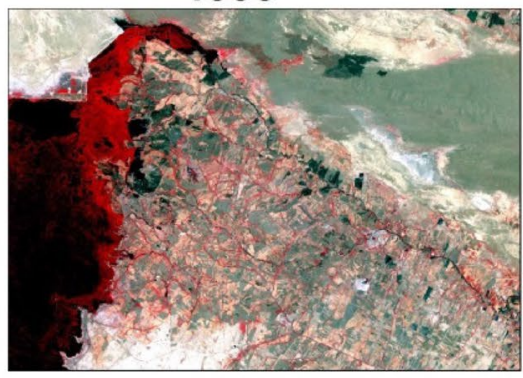

2004

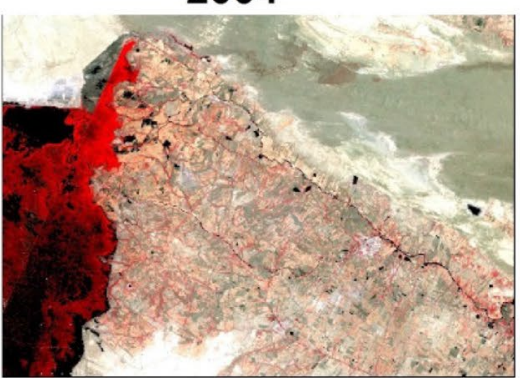

2012

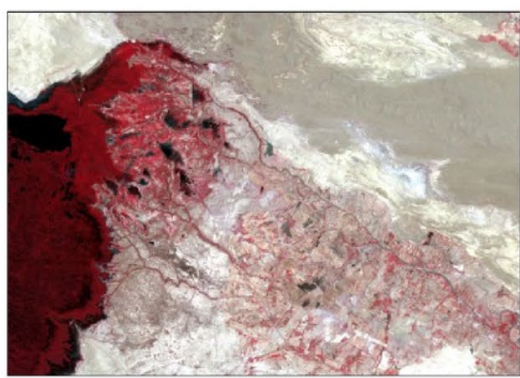

1985

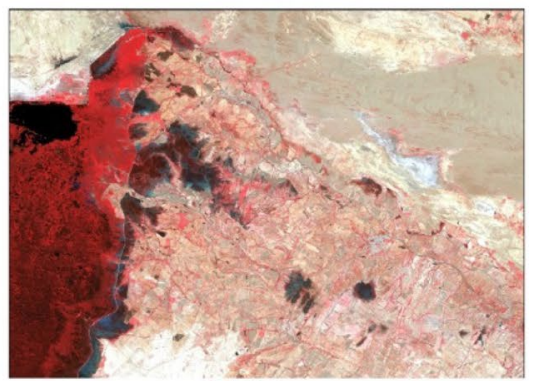

1998

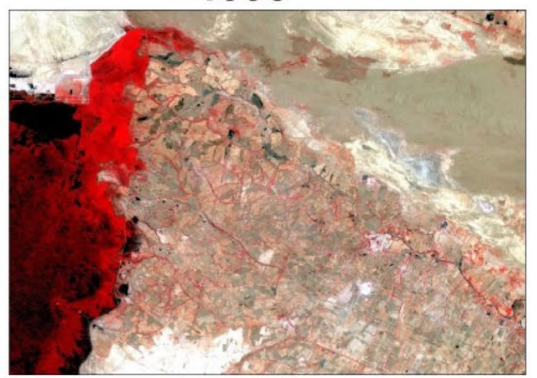

2007

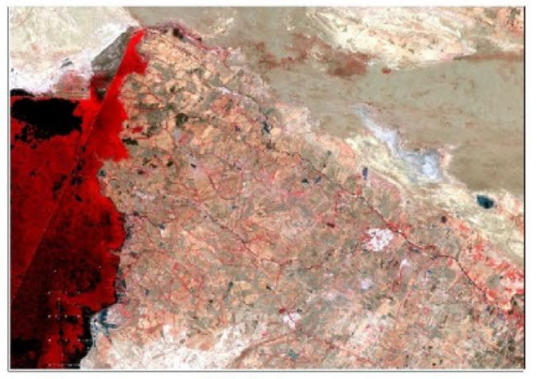

2014

Karkheh Delta

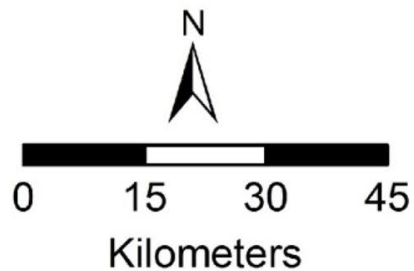

Fig. 8 Changes in area of the Karkheh Delta from 1973 to 2016 based on Landsat 5, 7, 8 images 
Fig. 9 Schematic of changes in the area of the Karkheh Delta from 1973 to 2016
In contrary to gravel, distribution map of sand is regular and from the head towards the base, the value increases. In north of delta's base due to vicinity of sand dunes, sand value is maximum. Also, in south of delta's base, because of vicinity of sabkha (resulted from dried Hor Al-Azim), sand value increases but in comparison with the northern part, it is lower.

Silt distribution map in this delta shows the highest value of silt in the head and middle of delta, whereas in the base (especially north of base) we can see the minimum value. Generally looking, it can be mentioned that silt value from head to base has a decreasing trend which is irregular in some areas. The reason for this is plurality of existing channels in Karkheh delta and also vicinity of various environments like alluvial fan, sand dunes, sabkha and lagoons. Considering the effect of near environments on change of silt value, sand dunes in the north can be pointed out which due to exist of mature sands, silt reaches to its lowest value in this part of delta. Clay value in the head of Karkheh delta has more frequency and towards the south it decreases (Fig. 13). Therefore, generally same as Karoon and Jarrahi Deltas, by moving from 
Fig. 10 Increase of area (particularly in the northern part) in Karkheh Delta based on Landsat 5 (1973) and 8 (2016) images
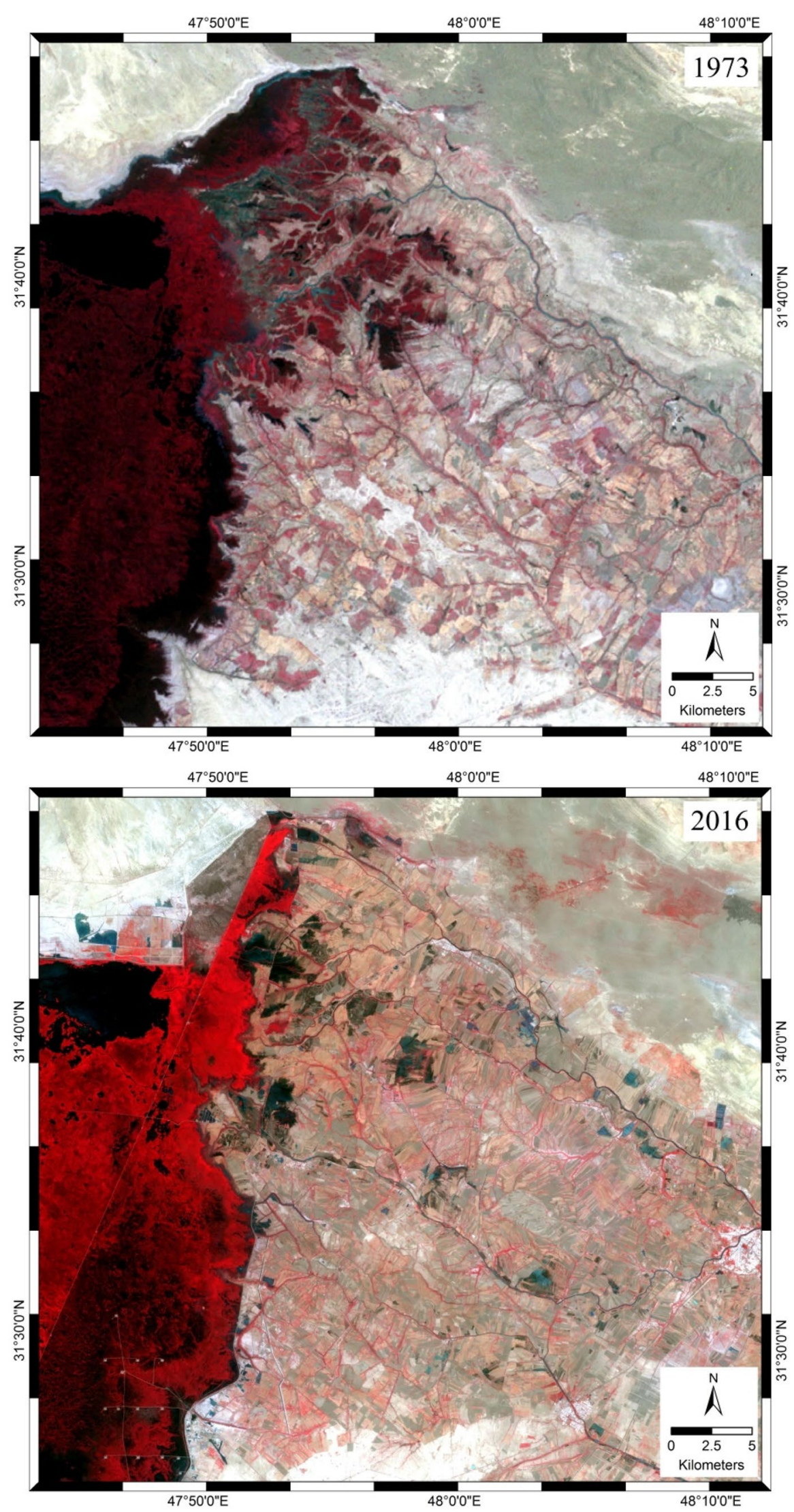
Fig. 11 Changes in area of the Karkheh Delta from 1973 to 2016

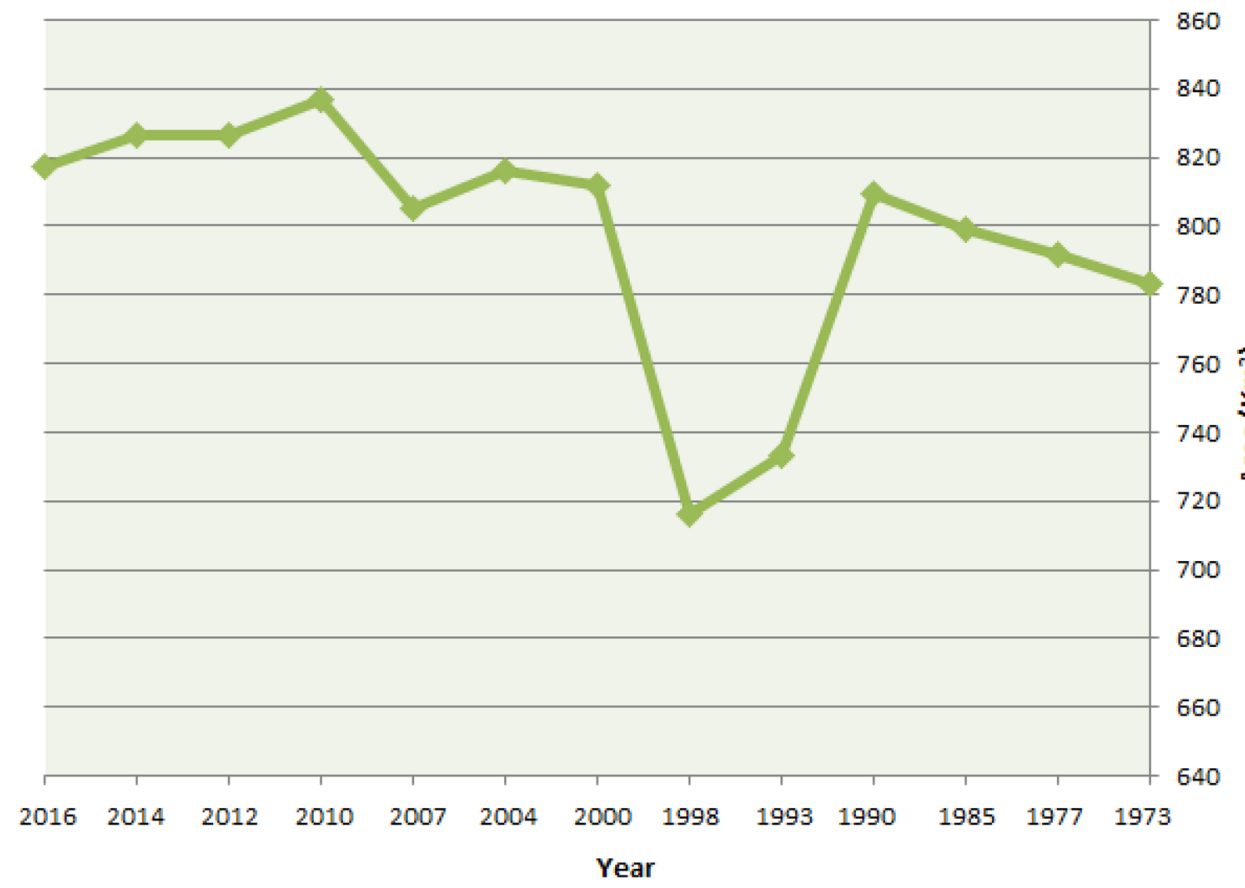

Table 2 Changes in area of the Karkheh delta from 1973 to 2016

\begin{tabular}{llllllllllllll}
\hline 1973 & 1977 & 1985 & 1990 & 1993 & 1998 & 2000 & 2004 & 2007 & 2010 & 2012 & 2014 & 2016 & Year \\
783 & 791 & 799 & 809 & 733 & 716 & 812 & 816 & 805 & 837 & 826 & 826 & 817 & Area $\left(\mathrm{Km}^{2}\right)$ \\
\hline
\end{tabular}

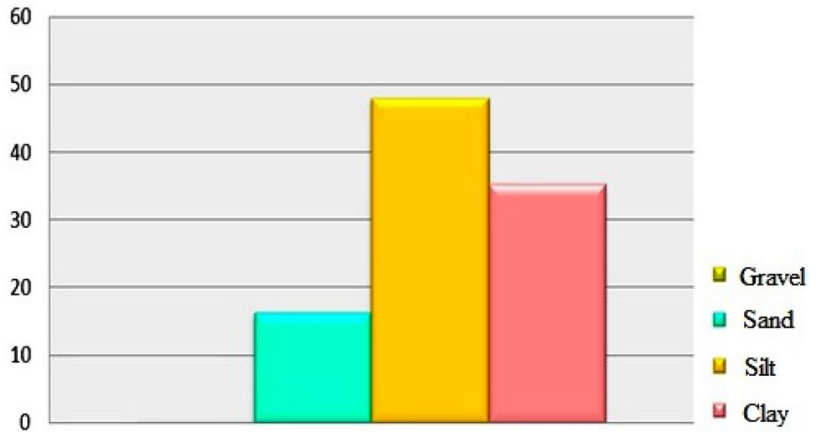

Fig. 12 The average of gravel, sand, silt and clay sediments the Karkheh Delta

Table 3 Maximum, minimum and average of sediments in the Karkheh delta

\begin{tabular}{lllll}
\hline & Gravel & Sand & Silt & Clay \\
\hline Max & $\% 0.55$ & $\% 43.25$ & $\% 53.78$ & $\% 48.7$ \\
Min & $\% 0.28$ & $\% 4.61$ & $\% 45.57$ & $\% 10.9$ \\
Ave & $\% 0.44$ & $\% 16.2$ & $\% 48.05$ & $\% 35.3$ \\
\hline
\end{tabular}

the head of delta towards its base, silt value increases and clay, sand and gravel decrease. Indeed, the changes are a little irregular here. These changes explain the decrease of sediments' size from the head to the base of Karkheh delta due to decrease of river's slope and consequently decrease of its energy. Bird [5] confirmed this matter.

Based on Shepard [17] classification, silty clay, clay silt, silt, sandy silt and clay-silt-sand were identified which comparing to Karoon and Jarrahi Deltas it shows more variety. Distribution of different sediments show that the described delta is a fine-grained one since silty and clay sediments are abundant. In the head of this delta, sediments are silty clay type which gradually changes to clay silt type. Then in the middle of delta, silt is observed which towards the base of delta changes to clay silty sand and sandy silt.

\subsection{Depositional environment of Karkheh delta}

Identification of different sedimentary sections of Karkheh Delta is very difficult. Channels, flood plain and sabkha can be easily recognized in this delta but identification of crevasse and levee sediments due to expansion of agricultural activities and other human activities in this delta is very hard. Karkheh Channel in this interval 
Table 4 Salient features of Karkheh delta and selected river-dominated deltaic systems. Sources of data as follows: Comeman and Wright 18; Milliman and Meade (1983); Bogen (1987); Bornhold et al. (1986); Lapointe 14; Coleman and Huh16

\begin{tabular}{|c|c|c|c|c|c|c|c|}
\hline Delta & Karkheh & Mississippi & Danube & Po & Huang $\mathrm{He}$ & MacKenzie & Tunsberg dalbre \\
\hline Country & Iran & United States & Romania & Italy & China & Canada & Norway \\
\hline Drainage area $\left(\mathrm{Km}^{2}\right)$ & 51,643 & $3,344,000$ & 779,500 & 71,700 & 865,100 & $1,448,000$ & 13,600 \\
\hline Mean annual discharge $\left(\mathrm{m}^{3} \mathrm{~s}^{-1}\right)$ & 134.2 & 15,631 & 6499 & 1484 & 1552 & 9100 & - \\
\hline Area $\left(\mathrm{Km}^{2}\right)$ & 879 & 28,568 & 4345 & 13,398 & 36,272 & 13,000 & 25 \\
\hline Gradient $\left(\mathrm{m} \mathrm{km}^{-1}\right)$ & 0.1 & 0.02 & 0.152 & 0.05 & Flat & 0.05 & $17-35$ \\
\hline Wave height & - & Very low & Very low & Very low & Low & Low & Low \\
\hline Tide range & - & Microtidal & Microtidal & Microtidal & Microtidal & Microtidal & Microtidal \\
\hline Sediment & Silt/mud & Silt/mud & Fine sand & Fine sand & Silt/mud & Fine sand & Gravel \\
\hline Receiving basin & Hor Al-Azim marsh & Golf of Mexico & Black sea & Adriatic sea & Yellow sea & Beaufort sea & North sea \\
\hline
\end{tabular}

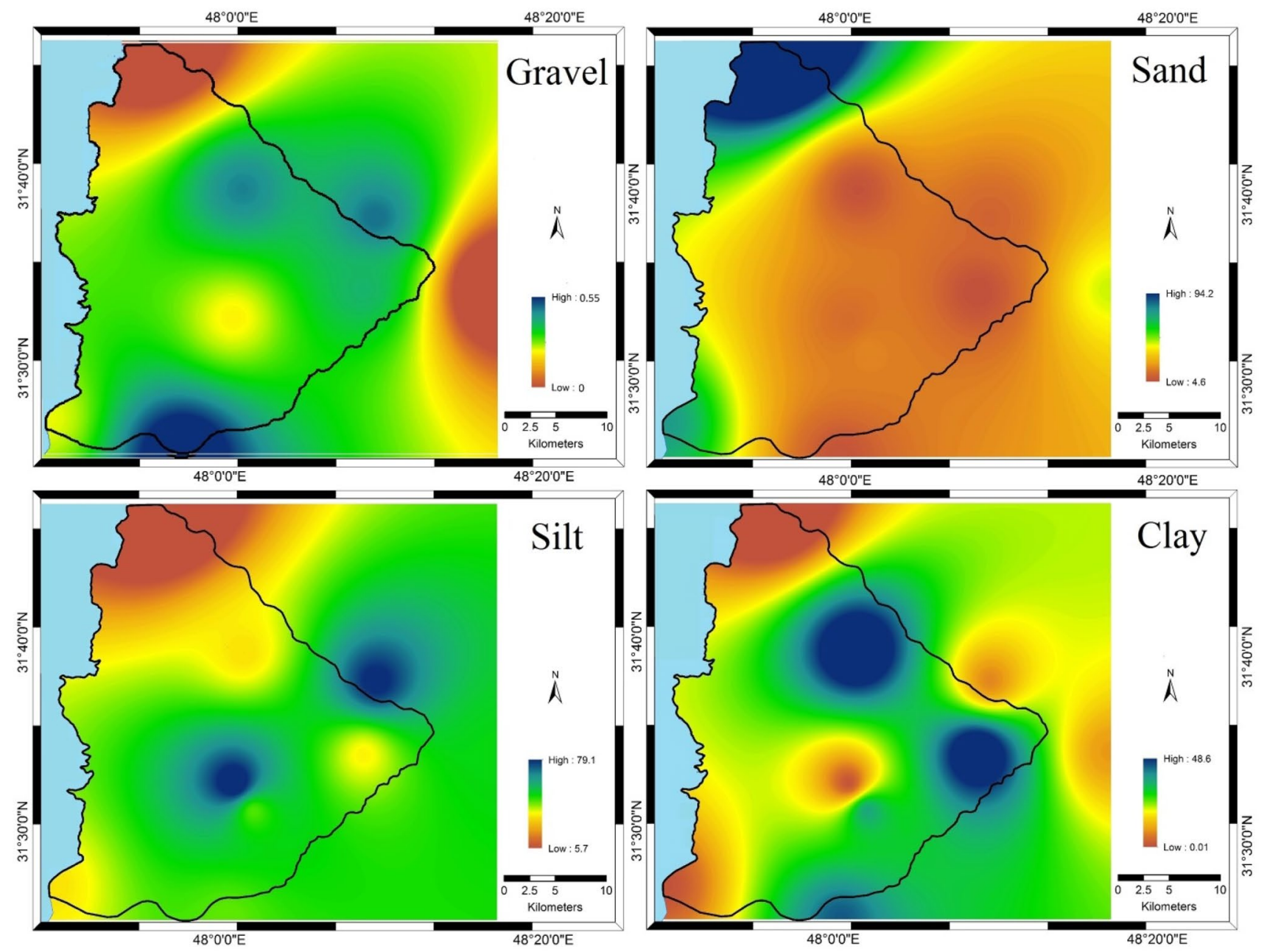

Fig. 13 Distribution map of gravel, sand, silt and clay sediments in the Karkheh Delta

has a straight and slightly meandering shape. River curvature is small and consequently there does not exist any lateral migration of channel. Paleo-evidences show that firstly the Karkheh Channel was in southern part of delta, and then this channel was abandoned and changed its route to the center and finally the north. As it can be seen now, most activity of this delta takes place in the northern part. 
Although some of these channels changed their way because of human activities, creation of various branches of Karkheh was in a way that due to heavy sedimentary load at the beginning the main channel's dip and river flow rate became lower and then getting affected by later floods, levees were dug and formed the shorter and higher-dip exit channels. Later on, as result of deposition some of these branches were closed some other ones stayed as minor branches of Karkheh in which deposition still occurred and formed small deltas. The newest channels are observed in the northern part of Karkheh delta as this part of delta is still active. There is the same story about Mississippi delta (Bird) [5] and Jarrahi Delta (Abyat et al.) [3]. Dip gradual decrease in karkheh Delta is also effective in branching the main channel of Karkheh so that in lower part of delta because of low dip and elevation, many branches are split from the main channels, whereas in the upper part of Karkheh due to higher dip and elevation, the number of branches are very lower (Fig. 4). Another reason is existence of much sand in this delta which results in weaker levees.

Flood plain of Karkheh river in Karkheh Delta has the more expansion than the upper parts, having a width of almost $41 \mathrm{~km}$. The northern part of this plain is limited to sand dunes and has a low expansion, whereas the southern part is highly expanded. The type of sediments on this plain in this interval is mostly silty with a percentage of clay but in the parts near to channel, fine sand is also seen.

In addition to channel and flood plain, sabkha can also be observed in this delta. The mentioned sabkha is continental and was created by drying Hor Al-Azim Marsh. Similar sabkha was reported by Abyat et al. [4] in the northern part of Jarrahi Delta and in vicinity of Shadegan Marsh. As said before, recognition of crevasse and levees is difficult. In this research, a crevasse was identified in south of Karkheh Delta and is formed of fine-grained sediments of silts and sometimes clay silt. Another reason for lack of crevasses in this delta is that channels of Karkheh delta do not have much curvature. Levees can be seen in older images and in small abandoned channels (especially in south of delta).

\section{Conclusion}

Karkheh Delta is one of the Quaternary transitional depositional environments in west of Khuzestan Plain. Head of this delta is located in Susangerd City and ends to Hor AlAzim Marsh. Karkheh Delta has a triangular shape and its base is almost straight. In a general looking, according to existing mail channels, Karkheh Delta can be divided into two deltas; the northern delta named as Karkheh Delta and the southern one named as Karkheh -e- Noor Delta.
The northern delta from north towards south is divided into three smaller deltas; Bostan, Sableh and Neisan.

Considering activity, this delta is divided into two parts; active and inactive. Based on Galloway, [7] Karkheh Delta is a river-dominated delta (type 14). In this type of delta, direction of deposition is parallel to the depositional basin's dip which due to east-west dip of this delta, its sedimentation has the same trend. This delta is river-dominated for some reasons amongst which having no impact of tides and waves changes, slight dip of delta plain, big suspended load and shortage of large-grained sediments can be mentioned. Based on Orton and Reading [16] classification, Karkheh Delta is placed in fine-grained (muddy) delta group due to prevailing silt and clay. In terms of sediment transportation and deposition process, this delta is a constructive delta. Comparing satellite images from 1973 to 2016 , it is confirmed that this rive is constructive. In the year 1973, the delta had an area of $783.3 \mathrm{~km}^{2}$, however in 2016 this value reached to $817 \mathrm{~km}^{2}$.

In order to study sedimentology of this delta, 25 samples were taken. Sediment sizing analysis results show that silt is the most abundant sediment on average in this delta and clay, sand and gravel are in next abundance. Generally, by moving from the head of delta towards its base, silt value increases and clay, sand and gravel decrease. The reason for this observation is decrease of river's slope and consequently decrease of its energy. Due to Shepard [17] classification, in Karkheh delta, silty clay, clay silt, silt, sandy silt and clay-silt-sand were identified. Recognition of different sedimentary sections of Karkheh Delta is very difficult. Channels, flood plain and sabkha can be easily recognized in this delta but identification of crevasse and levee sediments due to expansion of agricultural activities and other human activities in this delta is very hard.

\section{Compliance with ethical standards}

Conflict of interest The authors declare that have no conflict of interest.

Ethical approval All procedures performed in studies involving human participants were in accordance with the ethical standard of the institutional and/or national research committee and with the 1964 Helsinki declaration and its later amendments or comparable ethical standards.

Informed consent Informed consent was obtained from all individual participants included in the study.

Open Access This article is licensed under a Creative Commons Attribution 4.0 International License, which permits use, sharing, adaptation, distribution and reproduction in any medium or format, as long as you give appropriate credit to the original author(s) and the source, provide a link to the Creative Commons licence, and indicate if changes were made. The images or other third party material in this 
article are included in the article's Creative Commons licence, unless indicated otherwise in a credit line to the material. If material is not included in the article's Creative Commons licence and your intended use is not permitted by statutory regulation or exceeds the permitted use, you will need to obtain permission directly from the copyright holder. To view a copy of this licence, visit http://creativecommons .org/licenses/by/4.0/.

\section{References}

1. Abyat A, Azhdari A, Jodaki M, Darvishi Khatoni J, Yousefi M (2015) Study of Quaternary sedimentary environments in Khuzestan plain. Geological Survey of Iran, Ahwaz, p 272

2. Abyat A, Azhdari A, Jodaki M, Darvishi Khatoni J (2017) Study and separation of Quaternary sedimentary environments in Khuzestan plain, Journal of Advanced Applied Geology, In press. 16.

3. Abyat A, Azhdari A, (2018) Sedimentology, Depositional Environment and Classification of Jarrahi River's Delta (South east of Khuzestan plain), Naghshe Ara, 84-101.

4. Abyat A, Azhdari A (2019) Almasi Kia, H, (2019) Khuzestan plain continental sabkhas, southwest Iran. Carbonates Evaporites 34:1469-1487. https://doi.org/10.1007/s13146-019-00494-3

5. Bird E, (2008). Coastal Geomorphology: An Introduction, 2nd Edition, John Wiley \& Sons, Ltd, 436.

6. Coleman M and Huh OK, (2004) Major deltas of the world: a perspective from Space, Coastal studies Institute, Louisiana State University, Baton Rouge, LA. 80302.,NASA report. 74.

7. Galloway WD, (1975) Process Framework for describing the morphologic and stratigraphic evolution of deltaic depositional systems, in Deltas, Models for Exploration, edited by M. L. Broussard, 86-98.

8. Heyvaert VMA (2012) Human-triggered avulsion in a semi-arid region (Karkheh river, lower Khuzestan, Iran). Abstracts, Quaternary International 279-280:121-232

9. Heyvaert VMA, Verkinderen, P, and Walstra J, (2013) Geoarchaeological research in Lower Khuzestan: state of the art. In: K. De
Graef K. and J. Tavernier (eds.) Susa and Elam. Archaeological, Philological, Historical and Geographical Perspectives. Brill, Boston-Leiden, 493-534.

10. Heyvaert VMA, Verkinderen $P$, Walstra J, Weerts HJT, Ooghe B (2012) The role of human interference on the channel shifting of the Karkheh River in the Lower Khuzestan plain (Mesopotamia, SW Iran). Quatern Int 251:52-63

11. Hooke RBL, Rohrer WL (1979) Geometry of alluvial fans: the effect of discharge and sediment size. Earth surf Processes 4:147-166

12. Howard AD, (1980) Thresholds in river regimes. In: Thresholds in Geomorphology (Ed. by D. R. Coates \& J. D: Vitek), 227-258.

13. Kuenzer C, van Beijma S, Gessner U, Dech S (2014) Land surface dynamics and environmental challenges of the Niger Delta, Africa: Remote sensing-based analyses spanning three decades (1986-2013). Appl Geogr 53:354-368

14. Lapointe $M$, (1990) The MacKenzie. In: The Rivers cape (Ed. by Wolman MG, Church M, Newbury R, Lapointe, M, Frenette, M, Andrews, ED, Lisle, TE, Buchanan, JP, Schumm SA and Winkley BR), The Geology of North America, Geological Society of America, 1, 292-295.

15. Milliman JD, Meade RH (1983) World - wide delivery of river sediment to the Oceans. J Geol 91(1):1-21

16. Orton GJ, Reading HG (1993) Variability of deltaic processes in terms of sediment supply, with particular emphasis on grain size. Sedimentology 40(3):475-512

17. Shepard FP (1954) Nomenclature based on sand-silt-clay ratios. J Sediment Res 24(3):151-158

18. Wright LD, (1985) River deltas. In: Coastal Sedimentary Environments (Ed. by Davis RA), 1-76.

19. Zheng Q, Zeng Y, Deng J, Wang K, Jiang R, Ye Z (2017) “Ghost cities" identification using multi-source remote sensing datasets: A case study in Yangtze River Delta. Appl Geogr 80:112-121

Publisher's Note Springer Nature remains neutral with regard to jurisdictional claims in published maps and institutional affiliations. 